\title{
Avaliação da aprendizagem matemática no primeiro ano do Ensino Médio de uma escola da rede pública estadual de Mato Grosso: entre a teoria e a realidade
}

Assessment of mathematics learning in the first year of high school at a public school of the state of

Mato Grosso: between theory and reality

Evaluación del aprendizaje de las matemáticas en el primer año de Secundaria en una escuela pública estatal en Mato Grosso: entre la teoría y la realidade

Recebido: 13/10/2021 | Revisado: 19/10/2021 | Aceito: 22/10/2021 | Publicado: 24/10/2021

\author{
Sandra Terezinha Marchiori \\ ORCID: https://orcid.org/0000-0003-1172-260X \\ Universidade Federal de Mato Grosso, Brasil \\ E-mail: marchioriprofmat@gmail.com \\ Marta Maria Pontin Darsie \\ ORCID: https://orcid.org/0000-0002-1255-6546 \\ Universidade Federal de Mato Grosso, Brasil \\ E-mail: marponda@uol.com.br
}

\begin{abstract}
Resumo
Este artigo apresenta resultados de uma pesquisa que tem como objeto a avaliação da aprendizagem na matemática. A questão central é compreender como a avaliação está sendo concebida e praticada por professores das turmas do primeiro ano do Ensino Médio. Para isso, buscou-se analisar o processo avaliativo apresentado nos documentos oficias que orientam a Educação Básica no Brasil e em Mato Grosso (MT) e conhecer a concepção e a prática de avaliação da aprendizagem dos docentes desta etapa. A pesquisa foi desenvolvida em uma Escola Estadual do Município de Sinop/ MT, envolvendo três professores de Matemática. A análise e interpretação dos dados produzidos se desenvolveram à luz dos princípios norteadores da avaliação formativa, conforme as acepções epistemológicas de Luckesi (2011; 2018), Perrenoud (1999), Darsie (1998), Hoffmann (2018), Sacristán e Gómez (1998) e Libâneo (2006). Optou-se pela pesquisa qualitativa exploratória com análise interpretativa de documentos oficiais e dos dados gerados junto aos professores tendo questionário e entrevista como instrumento de investigação. Tal instrumento objetivou verificar de que forma os docentes de Matemática percebem os estudantes ingressantes no Ensino Médio nos seguintes aspectos: postura diante do estudo e conhecimento matemático básico construído no Ensino Fundamental. Em acréscimo, como esses saberes são diagnosticados e avaliados, pelos professores, durante o ano letivo. Nessa conjectura, os resultados apontaram uma ruptura no processo de ensino e no formato de avaliação na passagem do Ensino Fundamental (Ciclo de Formação Humana) para o Ensino Médio (seriado), fator que incide no desempenho do aluno.
\end{abstract}

Palavras-chave: Avaliação da aprendizagem; Educação matemática; Concepções e práticas docentes.

\begin{abstract}
This article presents results of a research that has as its object the mathematics learning assessment process. The central issue is to understand how assessment is being conceived and practiced by teachers in the first year of high school. For this, we sought to analyze the evaluation process presented in official documents that guide Basic Education in Brazil and in Mato Grosso (MT), and to know the conception and practice of evaluating of teachers at this stage. The research was developed in a public school of the state Of Mato Grosso, in Sinop/MT, involving three Mathematics teachers. The analysis and interpretation of the data produced were developed in the light of the guiding principles of formative assessment, according to the epistemological meanings of Luckesi $(2011 ; 2018)$, Perrenoud (1999), Darsie (1998), Hoffmann (2018), Sacristán and Gómez (1998) and Libâneo (2006). We opted for exploratory qualitative research with interpretive analysis of official documents and data generated from questionnaires and interview answered by the teachers as an investigative instrument. This instrument aimed to verify how Mathematics teachers perceive students entering high school in the following aspects: attitude towards the study and basic mathematical knowledge built in elementary school. In addition, how this knowledge is diagnosed and evaluated by teachers during the school year. In this conjecture, the results pointed to a rupture in the teaching process and in the evaluation format in the passage from Elementary School (Cycle of Human Formation) to High School (serial), a factor that affects student performance.
\end{abstract}

Keywords: Learning assessment; Mathematics education; Conceptions and teaching practices. 


\begin{abstract}
Resumen
Este artículo presenta los resultados de una investigación que tiene como objeto la evaluación del aprendizaje en matemáticas. El tema central es comprender cómo la evaluación está siendo concebida y practicada por los profesores en el primer año de la escuela secundaria. Para ello, se buscó analizar el proceso de evaluación presentado en documentos oficiales que orientan la Educación Básica en Brasil y Mato Grosso (MT) y conocer la concepción y práctica de evaluar el aprendizaje de los docentes en esta etapa. La investigación se desarrolló en una Escuela Pública del Municipio de Sinop / MT, involucrando a tres profesores de Matemáticas. El análisis e interpretación de los datos producidos se desarrolló según los significados epistemológicos de la evaluación formativa, de Luckesi (2011; 2018), Perrenoud (1999), Darsie (1998), Hoffmann (2018), Sacristán. y Gómez (1998) y Libâneo (2006). Se optó por una investigación cualitativa exploratoria con análisis interpretativo de documentos oficiales y datos generados con docentes utilizando cuestionarios y entrevistas como instrumento de investigación. Este instrumento tuvo como objetivo verificar cómo los profesores perciben a los estudiantes que ingresan a la escuela secundaria en los siguientes aspectos: actitud hacia el estudio y conocimientos matemáticos básicos construidos en la escuela primaria. Además, cómo estos conocimientos son diagnosticados y evaluados por los maestros al final del año escolar. En esta conjetura, los resultados del estudio apuntaban a una ruptura en el proceso de enseñanza y en el formato de evaluación en la transición de la Escuela Primaria a la Escuela Secundaria, factor que incide en el desempeño académico de los estudiantes.
\end{abstract}

Palabras clave: Evaluación del aprendizaje; Educación matemática; Docencia de concepciones y prácticas.

\title{
1. Considerações Iniciais
}

A Educação Básica no Estado de Mato Grosso tem sido alvo de críticas, especialmente por parte de governo estadual e por sua bancada na câmara ${ }^{1}$ nos discursos nas mídias ${ }^{2}$ e em negociações com a categoria entre outros. Diante disso, fez-se um estudo com a intencionalidade de revelar alguns aspectos que buscam compreender o rendimento dos estudantes do primeiro ano do Ensino Médio (doravante EM), visto que se trata de uma etapa considerada um gargalo, em termos de retenção e abandono. Direcionado pela observância do alto índice de retenção dos estudantes do primeiro ano do EM da Escola Estadual do Município de Sinop Mato Grosso (MT), contexto de estudo, constatou-se, por meio de dados apresentados no site do INEP, no ano de 2018 que o problema não é exclusividade da instituição pesquisada que teve em torno de $19 \%$ dos estudantes retidos, mas das escolas da rede pública de Educação Básica em nível estadual, num percentual de 22,6\% e nacional 16,9\% para o mesmo $\mathrm{ano}^{3}$.

Diante desse contexto, esta investigação teve como proposição verificar se a concepção de avaliação da aprendizagem, estabelecida nos documentos normativos da Educação Básica e conceituada nos estudos dos teóricos especialistas sobre o tema, está presente na compreensão e na prática avaliativa dos professores de matemática, atuantes no primeiro ano do EM.

Para tanto, fez-se um mapeamento do rendimento dos estudantes, utilizando uma pesquisa prévia realizada na instituição em questão e, posteriormente, nas informações coletadas no site oficial de publicação de dados do Ministério da Educação (MEC), por meio do Instituto Nacional Estudos e Pesquisas Educacionais - Anísio Teixeira (INEP), para traçar um paralelo do rendimento dos estudantes da rede estadual de MT com a média nacional e com os dados auferidos na escola pesquisada.

Para auxiliar a compreensão sobre os fundamentos da avaliação de aprendizagem escolar, a investigação se apoiou nas acepções teóricas de especialistas sobre o tema, como Luckesi (2011, 2018) Hoffmann (2018), Libâneo, (2006) Sacristán e Gómez (1998), Perrenoud (1998) e Darsie (1996), além de documentos norteadores da Educação Básica como a Lei de Diretrizes e Base da Educação Nacional - LDB (1996), Base Nacional Comum Curricular - BNCC (2017), Documento de Referência Curricular do Estado de Mato Grosso - DRC-MT (2018) e Orientações Curriculares para a Educação BásicaOCEB (2010).

\footnotetext{
${ }^{1}$ https://www.rdnews.com.br/executivo/deputado-quer-resultado-do-ideb-em-placas-secretaria-ja-descarta/28753

${ }^{2} \mathrm{https}$ ///www.conexaopoder.com.br/poderes/mauro-critica-gestao-do-pt-na-educacao-e-questiona-sindicatos-somos-o-22-no-ideb/156795;

${ }^{3}$ https://qedu.org.br/estado/111-mato-grosso/taxas-rendimento/rede-estadual/urbana?year=2018
} 
Dada abrangência do processo que envolve a avaliação da aprendizagem e seus aspectos metodológicos, a descrição da realidade escolar é apresentada sob a ótica do sujeito interno ao processo educacional. As informações foram obtidas por meio da análise da proposta avaliativa do Projeto Político Pedagógico (PPP) da escola, do Planejamento Anual (PLA) dos professores da disciplina de Matemática e das respostas dos investigados às indagações feitas em questionário.

Os colaboradores são professores que vivenciam o dia a dia da prática educativa, o que lhes confere competência para relatar, segundo seus pontos de vista, como é percebida a postura dos estudantes com relação ao compromisso com o estudo, além da percepção de como os conhecimentos matemáticos foram construídos na etapa anterior. Seus relatos ajudaram a entender o contexto da avaliação e também a maneira na qual se realiza a aferição dos conhecimentos ensinados aos estudantes. Suas narrativas apontam para os fatores internos e externos que incidem sobre o processo de efetivação da avaliação da aprendizagem que causa tensionamento entre a teoria e a realidade.

Assim, para melhor sistematização do estudo supracitado, este artigo articular-se-á em tópicos, que tratarão do rendimento escolar dos estudantes do EM; da avaliação da aprendizagem escolar, da descrição da realidade vivenciada pelos docentes no lócus da pesquisa; dos resultados da investigação e, por fim, as Considerações Finais.

\section{Metodologia}

Por se tratar de uma investigação em educação, optou se pela abordagem qualitativa exploratória de cunho interpretativo dos resultados, tendo como instrumento de produção de dados: questionário entrevista e análise documental. Em tais aspectos se ampara teoricamente nas referências de Bogdan e Biklen (1994) no qual apresentam cinco características básicas que configuram a pesquisa qualitativa em educação, quais sejam. 1- Na investigação qualitativa a fonte direta de dados é o ambiente natural, constituindo o investigador o instrumento principal. 2. A investigação qualitativa é descritiva. 3. Os investigadores qualitativos interessam-se mais pelo processo do que simplesmente pelos resultados ou produtos. 4. Os investigadores qualitativos tendem a analisar os seus dados de forma indutiva. 5. O significado é de importância vital na abordagem qualitativa. Toda essa base mostra que o pesquisador precisa ter o cuidado de revelar e considerar os diferentes pontos de vistas dos participantes a luz de suas percepções, em consonância com a problemática estudada, com o arcabouço teórico atento aos detalhes que culminarão no resultado da pesquisa. A pesquisa exploratória por sua vez, possibilita maior aproximação com o fenômeno observado e propicia a análise apurada de seus aspectos mais particulares. Desse modo o torna evidente para que seja possível construir conjecturas a partir dos seus elementos. Gil (2008, p. 4) infere que "pode-se dizer que estas pesquisas têm como objetivo principal o aprimoramento de ideias ou descoberta de intuições" ao fazer emergir características até então despercebido pelos observadores.

Os colaboradores foram três professores regentes no primeiro ano do EM na disciplina de matemática que atuam ha três anos ou mais na escola Lócus, e suas narrativas propiciou verificar como estes docentes percebem os estudantes ingressantes no E M nos seguintes aspectos: a postura diante do estudo; o conhecimento matemático básico construído no EF e como esses saberes são diagnosticados e avaliados pelos professores durante o ano letivo. Os instrumentos utilizados para obtenção de dados foram: um questionário com perguntas abertas, enviados aos participantes por e-mail em correspondência única; uma entrevista semiestruturada realizada presencialmente com um roteiro norteador elaborado com intuito de preencher lacunas informativas deixadas pelas respostas do questionário, com gravação de áudio para posterior transcrição. Ambos com objetivo de obter respostas qualitativas sobre o objeto de investigação, a saber: a) Com base em sua experiência profissional, você percebe que os estudantes concluintes do nono ano alcançaram o nível de conhecimento matemático suficiente para dar prosseguimento aos estudos no EM? b) Quais instrumentos você utiliza para verificar a evolução da aprendizagem dos alunos e, com qual periodicidade você os avalia? c) Quais critérios considera pertinente observar, (na atribuição de notas/ médias dos bimestres e/ ou do ano letivo) que implica no desempenho do estudante durante o período? d) Quando se refere aos conceitos 
básicos e operações matemáticas, em sua opinião, quais aprendizagens seriam indispensáveis o aluno ter construído no EF, que são pré-requisito conseguir avançar no EM?

As informações obtidas com os instrumentos de investigação foram trianguladas com a tendência de avaliação proposta no Projeto Político Pedagógico da Escola (PPP) e no Planejamento Anual (PLA) dos professores de matemática do primeiro ano do EM, sendo ainda relacionada com o modelo de avaliação sugerida nos documentos oficias que normatizam a educação básica na atualidade. Como estratégia de análise e apresentação dos dados, decidiu se pela Análise Textual Discursiva (ATD) de Moraes e Galiazzi (2007) e seus três elementos; unitarização, categorização e produção do metatesto e comunicação dos resultados.

\section{Referencial Teórico}

$\mathrm{O}$ arcabouço teórico referente à temática apresentada se estrutura em quatro seções: o retrato do rendimento dos estudantes ingressantes no Ensino Médio de escolas públicas; a concepção de avaliação da aprendizagem escolar; os direcionamentos do processo avaliativo em documentos de base legal que disciplina a educação básica brasileira; e a descritiva da realidade encontrada em escolas de Ensino Médio no estado de Mato Grosso.

\subsection{O retrato do rendimento dos estudantes do primeiro ano do Ensino Médio no ano de 2018}

Para falar sobre a avaliação em Matemática no primeiro ano do EM, na rede pública do Estado de Mato Grosso-entre a teoria e a realidade, adentrou-se no campo de pesquisa bibliográfica e documental para verificar o retrato do rendimento destes estudantes, no ano de 2018, no Brasil e também no Estado.

Iniciou-se a exploração por uma escola estadual de Sinop - MT, que atende alunos dos anos finais do Ensino Fundamental (EF) e turmas do EM, em sua maioria, num total de quarenta turmas dos quais dezesseis delas eram de primeiro ano. A pesquisa realizada teve como base as informações dos registros do Conselho de Classe e, posteriormente, confirmada pela Ata de Resultados Finais, emitida pelo banco de dados do Sistema de Gestão da Educação Básica (SIGEDUCA). Tais elementos mostraram que no ano de 2018 em torno de $19 \%$ dos estudantes do primeiro ano do EM ficaram retidos e outros 9,18\% não concluíram o ano letivo, sendo a Matemática uma das disciplinas contribuintes desta realidade. Vale ressaltar que a retenção só se efetiva quando o estudante não atinge a media 6,0 em pelo menos cinco disciplinas, das doze que compõe a matriz curricular. Esse estudo foi suficiente para mostrar o quantitativo significante de estudantes, em torno de 28,18\%, não foi promovido para o segundo ano da etapa, seja por retenção ou abandono. Dado bastante preocupante, se considerar que quase um terço dos estudantes estagnou no primeiro ano desse nível de ensino. Buscou-se, então, verificar se esse fenômeno apresentado é uma exclusividade dessa unidade escolar ou se, situação similar, tem ocorrido nas demais escolas da rede pública estadual no Brasil e em MT.

O sistema oficial de controle e informação da Educação Básica (INEP-MEC ${ }^{4}$ e parceiros) que tem como fonte principal de informação o censo escolar demonstra em dados numéricos a evolução de importantes índices que medem a qualidade da educação brasileira, o que serviu de parâmetro de comparação da realidade observada na escola de Sinop.

Os dados disponíveis pelo MEC, no período de 2010 a 2018, revelaram que a procura por vaga no EM (considerando os três anos da etapa) apresentaram uma oscilação negativa gradual de 11,08\% no intervalo de oito anos. No que tange ao Estado de MT, a busca por vaga para estudar no EM, acumulou uma queda de aproximadamente $11,89 \%$, no mesmo período. Diferença pouco expressiva, na casa de $0,81 \%$ para menos em termos percentuais.

\footnotetext{
${ }^{4}$ MEC- Ministério da Educação: https://www.gov.br/mec/pt-br
} 
A procura por ingresso nessa etapa, quando se refere ao primeiro ano, em 2010 o quantitativo representava $41,86 \%$ dos estudantes, em 2018 chegou a 36,49\% na média nacional.

No Estado de MT, a situação se inverte nesse período, se comparado à realidade nacional. Houve aumento de demanda para matricular nesta fase da Educação Básica. De fato, a oferta de matrícula que representava 43,39\% em 2010 passou para 44,59\% em 2018. Portanto tem-se uma queda 5,37\% de matrículas em nível nacional, mas um aumento de 1,2\% na demanda para o primeiro ano no MT.

Quando se refere aos rendimentos desses estudantes, este é demonstrado, segundo dados dos órgãos oficiais, pelo percentual de alunos matriculados e que, no encerramento do ano letivo, encontra-se em uma das seguintes condições de: aprovação, reprovação e abandono. Os estudantes com aprovação parcial estão inclusos na primeira categoria.

Estes dados são inseridos pela gestão escolar por meio do Censo Escolar no sistema do INEP que sistematiza os dados e divulga no site do instituto, para possa ser visualizado por toda sociedade.

Segundo estes dados (considerando os três anos), no Brasil, em 2018, a taxa de retenção atingiu a marca de 11,7\%, a de abandono foi de $7 \%$ e a de aprovação $81,3 \%$. Ou seja, $18,7 \%$ dos jovens foram submetidos ao retardamento do processo de conclusão da etapa e/ou a exclusão do sistema de ensino público.

A realidade verificada no Estado de Mato Grosso - considerando os três anos da modalidade regular, neste mesmo ano, mostrou que 16,6\% dos estudantes matriculados no EM foram retidos e outros 10,7\% não finalizaram o período oficial das aulas. Apesar de a aprovação ter sido a maior desde 2010, em 2018, o aproveitamento de 72,6\% deixou de fora do processo educacional $27,4 \%$ dos estudantes. Uma realidade distinta da nacional.

Sendo o primeiro ano do EM objeto da pesquisa, percebe-se que este representa o gargalo da etapa e propulsor dos dados negativos, pois, apesar de haver maior percentual de matrícula, dentre os três anos, também ranqueia a média de reprovação e abandono, tanto em âmbito nacional quanto estadual.

Com efeito, no Brasil ${ }^{5}$, em 2018, a retenção destes estudantes foi 16.9\%, sendo que em MT, esse percentual foi mais elevado chegando à marca de 22,6\%. O abandono, no estado ficou em torno de 13,8\%, o que também apresenta diferença significativa se comparada aos $9.1 \%$ da média nacional. Completando o quadro, encontra-se a aprovação, com maior índice, em 2018, de 63,6\%, enquanto a média nacional foi de 74,0\%. Situação que exige dos legisladores e educadores uma análise cuidadosa da realidade que atravessa a Educação Pública da Rede Estadual de Educação Básica, na etapa EM regular, especialmente no primeiro ano.

A situação de aprovação, retenção e abandono dos estudantes do primeiro ano do EM, perpassa por um sistema avaliativo cujos preceitos teóricos serão apresentados na sequência.

\subsection{A avaliação da aprendizagem escolar}

A avalição da aprendizagem, segundo Luckesi (2018), foi um termo cunhado por pelo educador norte - americano Rafh Tyler em 1930, cuja intenção era fazer frente aos altos índices de retenção dos estudantes daquele país, dado caráter examinador e a sistemática excludente da avaliação vigente na época. O citado autor, também formulador do ensino por objetivo, buscou na nova prática educativa, uma forma de avaliação oposta aos "exames escolares, a denominação avaliação da aprendizagem, tendo em vista conceituar a prática de diagnosticar o desempenho dos estudantes em sua aprendizagem e subsidiar as decisões do educador na perspectiva de tornar eficiente sua ação" (Luckesi, 2018, p.94).

Na visão de Hoffman (2018, p. 148), a concepção da aprendizagem relacionada à prática avaliativa se efetiva "como a construção do conhecimento e organização das experiências dos sujeitos numa compreensão progressiva das noções - visão construtivista/ socioenteracionista". Ainda com referência ao ensino por objetivos e a avaliação da aprendizagem, Sacristãn e

${ }^{5}$ https://qedu.org.br/brasil/taxas-rendimento/rede-estadual/urbana?year=2018 
Gómez (1998) afirmam que estes se apoiam em estudos da psicologia, os quais orienta que a prática educativa siga uma sequência coerente obedecendo à estruturação do pensamento e o domínio da área e do conteúdo. Para que concluída a unidade instrucional, possa submeter os indivíduos ao diagnóstico da evolução do conhecimento construído sobre a temática estudada e, também, objetiva identificar as falhas do processo que possam ser contornadas o quanto antes.

Da proposta tyleriana, mencionada anteriormente, que se fundamenta na preocupação de estimar a aprendizagem e as diferenças de sua evolução entre os indivíduos do grupo,

surgiram os testes denominados criteriais, porque mediam capacidades e aprendizagens em relação ao um objetivo concreto que expressa uma competência, objetivo que funciona como modelo para decidir se ocorreu ou não a aprendizagem. O teste criterial diagnostica o grau de domínio de um conteúdo. O diagnóstico pretendia ser, assim, preciso e, servir para detectar dificuldades concretas em aprendizagens muito bem delimitadas que permitam a correção acertada (Sacristãn \& Gómez, 1998, p. 301).

Se o objetivo é a precisão nos instrumentos de teste, é possível afirmar que não se trata de uma tarefa fácil de ser planejada e executada, exige cautela em sua elaboração, aplicação e análise apurada na correção. Não é, portanto, simples estabelecer critérios, tampouco elaborar ferramentas a ser utilizados para coleta de informação, cujo objetivo é instrumentalizar uma avaliação que busque revelar as dificuldades reais dos estudantes para depois saná-las.

Faz-se necessário planejar cada instrumento ou cada parte de forma a atender a um objetivo concreto, ou a todos eles, de modo que possa alcançar o maior grau de exatidão possível na interpretação dos resultados, o que posteriormente direcionará a tomada de decisão do gestor (a) do ensino. Tal ideia respalda-se em Libâneo (2006, p. 196), o qual compreende a avaliação escolar "como um componente do processo de ensino que visa, através da verificação e qualificação dos resultados obtidos, determinar a correspondência destes com os objetivos propostos e, daí, orientar a tomada de decisão em relação às atividades didáticas seguintes".

O conceito de avaliação da aprendizagem apresentado por Luckesi (2018) é também denominado por Hoffmann (2018) como avaliação mediadora, termo usado também por Perrenoud (1998) ao qual, segundo este autor, se opõe a avaliação de excelência de caráter seletivo e classificatório. Hoffmann (2018) ainda assevera que a construção do conhecimento é um processo lento e gradativo que demanda investimento e compreensão. Trata-se, portanto, de desafiar, provocar e acompanhar os sujeitos em sua dinâmica de composição dos saberes, por meio do diálogo e da cooperação, da proposição de situações e, de espaços favoráveis à aprendizagem. Na concepção construtivista de aprendizagem, a avaliação mediadora situa-se,

Como ação provocativa do professor, desafiando o aluno a refletir sobre as situações vividas, a formular e a reformular hipóteses, encaminhando-se a um saber enriquecido. Dialogar entendido como a reflexão professor/aluno sobre o objeto de conhecimento. Acompanhar como favorecer o 'vir a ser' por meio de ações educativas que promovam a superação do aluno (Hoffmann, 2018, p. 148).

A avaliação mediadora da aprendizagem, portanto, é aquela que se associa a prática de sala de aula em todos os passos e, em todos os aspectos e detalhes, no sentido de propiciar um olhar objetivo sobre o rendimento do estudante no momento e suas potencialidades futuras.

O enfoque qualitativo da avaliação pressupõe uma função didática- pedagógica que, na perspectiva de Luckesi (2018), é alicerçada no planejamento de um currículo disciplinar e/ou integrado, cujos objetivos e metas compõe o padrão de qualidade projetado para o ensino de cada conteúdo. Darsie (1996, p. 48) corrobora nessa abordagem, quando salienta que a "essa intencionalidade se reflete em todos os aspectos do âmbito escolar e se faz fortemente presente na concepção, elaboração, execução e avaliação do currículo escolar". Para isso, planeiam-se os procedimentos pedagógicos inerentes às competências a 
serem desenvolvidas para aquele objeto de estudo, bem como, as habilidades básicas necessárias à compreensão e desenvolvimento de técnicas propícias à aplicação e resolução de problemas, sejam eles conceituais de aprendizagem ou de situações reais do cotidiano.

Relativamente à aprendizagem matemática, inclui-se toda demanda de conhecimento básico, dos fundamentos matemáticos, leitura e interpretação dos dados que emergem da situação observada, manipulação de algoritmos nas operações e aplicação de técnica na resolução de problemas. São estas habilidades que revelam o caráter significativo e social do conhecimento matemático.

Embora as denominações da avaliação a serviço da aprendizagem possam variar de uma época a outra, em sua essência, a intencionalidade não diverge tão significativamente. Prevalece sempre o caráter diagnóstico das aprendizagens, seja no início do ano letivo ou de uma unidade didática, quando se quer conhecer os estudantes/turma e verificar os conhecimentos precedentes dos estudantes; seja durante o processo em que se quer averiguar o grau de assimilação do que está sendo ensinado; ou no final do programa de ensino em que diagnostica os saberes construídos durante todo o processo por meio de uma avaliação globalizada. Nesse sentido, o objetivo final é sempre promover uma educação com melhor qualidade, que alcance a todos sem exceção de classe econômica, com o escopo, inclusive, de minimizar as desigualdades culturais e a exclusão social.

A avalição da aprendizagem encontra ressonância nos documentos que orientam o processo educativo e o sistema avaliativo no Brasil, objeto de discussão do próximo tópico.

\subsection{A avaliação da aprendizagem segundo os Documentos Oficiais que direcionam o processo educativo no Brasil e em Mato Grosso}

O Documento de Referência Curricular para o Estado de Mato Grosso (DRC, 2018) estabelece a avalição para a aprendizagem como parte dos preceitos norteadores da ação didática. Para isso, destacam as concepções, funções e instrumentos e ou estratégias correspondentes com a avaliação inclusiva proposta pela Base Nacional Comum Curricular (BNCC, 2017).

Entres as várias dimensões usuais no contexto educacional brasileiro, o foco desta pesquisa é a avalição centrada na aprendizagem, como resposta ao trabalho pedagógico realizado cotidianamente na sala de aula. O que a norma coloca para essa dimensão avaliativa está descrita com as seguintes características: a avaliação diagnóstica, formativa e somativa, tendo cada uma, por sua vez e, em cada momento do processo de ensino, função primordial para o sucesso do desenvolvimento pedagógico docente, para construção do conhecimento e a inclusão dos estudantes.

O Ensino Médio em MT (Mato Grosso, 2010) tem como ponto de partida as finalidades descritas na LDB (1996) e, pauta-se no cumprimento da função social. Para além da instrução formal dos estudantes, busca em sua proposta pedagógica promover espaços de inclusão que possibilite à população das classes econômicas inferiores identificar, acessar, compreender e prover suas necessidades relacionadas à produção cultural, científica e tecnológica. Necessidades estas que propiciem não apenas o acesso do alunado à escola, mas também sua permanência; contemple a diversidade de modalidades, a formação intelectual, assim como a integração dos saberes que se inter-relacionam com o mundo do trabalho. Nessa conjuntura, a avaliação, por se tratar do sistema público de ensino, abarca outras funções que perpassam a competência de acompanhar o desenvolvimento do pensamento e do conhecimento do estudante ao oferecer aos professores elementos, que subsidie o planejamento e norteie a ação didática.

Para além da competência anteriormente descrita, a avaliação abarca outros propósitos que vão desde "prestar contas à sociedade, fornecer elementos para o Sistema de Ensino e para a escola, de forma a poderem tomar decisões que cada vez mais aproximem os resultados alcançados das metas pretendidas, através da melhor utilização dos recursos disponíveis" (Mato 
Grosso, 2010, p. 77). Dessa forma, o direcionamento do processo educativo, etapa EM, em suas bases legais, visa garantir o direito de aprendizagem a todo cidadão brasileiro, sem distinção. Com isso, tem buscado nas últimas décadas a ampliação no número de vagas, bem como realização de estudos que instrumentalizem a equipe pedagógica de conhecimentos pertinentemente capazes de adequar a proposta da educação pública, com vistas a propiciar não somente o acesso, mas aprendizagens necessárias ao sucesso na vida escolar. Conhecimento que proporcione aos jovens estímulos para manter-se estudando até a conclusão da etapa.

Sendo a avaliação da aprendizagem escolar um importante instrumento de promoção de mudança no pensamento e nos resultados do processo educativo, esta deve estar em consonância com o contexto local e com a metodologia do que é ensinado.

Para melhor compreensão do cenário educativo do EM, especificamente nas turmas de primeiro ano, amparada pela intencionalidade de promover um processo avaliativo formativo, conforme preconiza as normas que regem a educação básica, apresenta-se na próxima sessão aspectos que possibilitem conhecer a realidade, as possibilidades e especificidades encontradas pelos docentes no interior das unidades educacionais da rede pública estadual de MT.

\section{4 $\mathrm{O}$ aspecto metodológico e a descrição da realidade encontrada na escola de Ensino Médio Regular da rede Estadual de Ensino}

O EM regular no Estado de MT é seriado, com possibilidade de retenção dos estudantes que não atingiram uma média aritmética de 60\% de assimilação do conteúdo, aferido por avaliações / exames durante o ano letivo.

Ações organizativas da SEDUC, por meio da PORTARIA No 684/2020/GS/SEDUC/MT, ${ }^{6}$ convalidam, no sistema de matrículas e registros, a efetivação de uma turma somente se ela tiver um número mínimo de trinta e cinco alunos, (eram de trinta em anos anteriores) excetos as turmas com estudantes com deficiência. O que acontece na prática, a depender da necessidade de vagas, coloca-se em torno de quarenta estudantes em uma única sala, uma vez que o estado tem o dever de garantir o acesso à escola a todos os cidadãos.

A matriz curricular do EM na modalidade regular, na instituição selecionada, é organizado de forma bimestral (quatro bimestres) e conta com doze disciplinas, sendo que a matemática tem duas aulas semanais em cada ano. O sistema SIGEDUCA ${ }^{7}$ é alimentado com conteúdo, frequência e notas escalares (de zero a dez), faz a parametrização e calcula a média aritmética ao final do ano letivo.

Os conceitos/notas são fechados bimestralmente após conselho de classe para emissão do boletim do rendimento dos estudantes por área/disciplina. Este é impresso e entregue aos pais e/ou responsáveis.

Ademais, é oportuno salientar que, em consonância com a lei de carreira dos servidores estaduais da educação, Lei Complementar $\mathrm{n}^{\circ} 50$, de $1^{\circ}$ de outubro de $1998^{8}$ art.36, cada professor, independente da forma de vínculo, atribui vinte horas aula em sala e dez horas atividade. Isso representa para um professor que atua exclusivamente no EM, o dever de ensinar a dez turmas um quantitativo de pelo menos trezentos estudantes semanais. De acordo com a legislação, o estado tem obrigação de garantir de forma universalizada um ensino de qualidade a todos, sem distinção, mas dentro deste contexto, não se pode afirmar que a aprendizagem alcance a todos de igual modo.

A Escola Estadual Nilza de Oliveira Pipino, foi à primeira unidade educacional criada no município em 1979. Situada na região central da cidade atende em dois turnos de funcionamento estudantes de todas as partes da unidade administrativa. Originado do diagnóstico da realidade escolar, o Projeto Político Pedagógico (PPP, 2019) descreve o perfil sócio econômico

${ }^{6}$ Diário Oficial- No 27.890 de 03 de dez, de 2020, p 82. https://www.iomat.mt.gov.br/.

${ }^{7}$ Sistema de registros acadêmicos por meio eletrônicos da Secretária do Estado de Mato Grosso.

${ }^{8}$ Lei Complementar $n^{\circ}$ 50. http://webcache.googleusercontent.com/search?q=cache: Cf0699TzoH4J:www.

gestao.mt.gov.br/download.php\%3FOp\%3Dlegislacao\%26arquivo\%3DLC_50-1998-160.pdf +\&cd=1\&hl=pt-BR\&ct=clnk\&gl=br\&client=firefox-b-d. 
dos alunos como parte de um estudo realizado com 5\% dos estudantes escolhidos aleatoriamente, o qual mostrou que a renda média mensal das famílias é de (três salários mínimos). Com média de idade de 17 anos, cerca de $70 \%$ dos estudantes são de bairros ou comunidades afastadas que fazem uso do transporte escolar. Destes $40 \%$ participam de algum modo da composição da renda familiar, sendo que $65 \%$ convivem com três ou mais pessoas na mesma residência. Dentre os participantes da pesquisa, 90\% declararam ter pai e/ou mãe como responsável, e que a internet é a principal ferramenta de informação.

No diagnóstico da realidade educacional, na dimensão que trata da avaliação e análise do monitoramento do processo de aprendizagem dos alunos, apresenta como marcador "precisa melhorar", isso por que;

Embora os professores observem a progressão dos alunos e suas dificuldades, no processo de aprendizagem, precisa melhorar o sistema de monitoramento. Isso se deve ao fato de o corpo docente ainda não ter adotado, de forma unânime, metodologias alternativas para a efetivação de uma avaliação formativa e processual eficiente [...] Outro ponto a ser destacado são os objetivos de aprendizagem contidos no SIGDUCA para o Ensino Fundamental, pois nem todos contemplam as habilidades trabalhadas durante a etapa (PPP. 2021).

Tal observação da proposta pedagógica mostra que existe ciência da necessidade em buscar melhorias no sistema avaliativo da escola, dada à heterogeneidade no entendimento do corpo docente frente à ação educativa. Na ótica da análise dos mecanismos de avaliação dos estudantes, a ciência é a mesma,

Os professores fazem uso de diferentes atividades para avaliar os alunos e agem conforme suas concepções educacionais. Entretanto, em alguns aspectos esses mecanismos avaliativos precisam ser aprimorados, uma vez que nem todas as atribuições de notas e/ou conceitos são discutidas entre os professores (PPP. 2021).

No que alude aos instrumentos utilizados pelos professores para aferir o conhecimento dos estudantes, o documento sugere uma variedade de opções que vão desde as "provas objetivas e dissertativas, avaliação unificada, seminários, trabalhos em grupo, debate, relatório individual, autoavaliação, observação, participação, frequência, caderno de campo e feiras, entre outros". No entanto, há o reconhecimento de que mesmo com tantas opções de procedimentos de recolha de informação que visa subsidiar o sistema avaliativo, este não atende em sua totalidade a concepção de avaliação da aprendizagem,

Pelo fato de as salas de aulas conterem muitos alunos, torna-se difícil o atendimento individualizado, principalmente em relação àqueles que apresentam dificuldades mais acentuadas, como é o caso dos alunos com déficit de atenção, especiais e aqueles que apresentam grande defasagem para a série. As notas são lançadas no sistema que produz uma média aritmética das notas lançadas, e neste sentido, a caminhada do aluno e sua evolução se descaracteriza em função dos números e em muitos casos, exclui mais do que forma (PPP, 2021).

Tais constatações explicam as dificuldades encontradas pelos professores em proceder ao diagnóstico acurado das assimilações dos conteúdos ensinados. Servindo-se deles na correção do curso da aprendizagem, dispondo de metodologias alternativas e/ou intervenções paralelas para fazer com que a aprendizagem alcance a maioria dos estudantes.

No Planejamento Anual (PLA) que é realizado em conjunto com todos os professores da disciplina para etapa Ensino Médio e inspirado nas competências especifica da Base Nacional Comum Curricular - BNCC tem como objetivo geral:

Reconhecer que a Matemática é uma ciência humana, fruto das necessidades e preocupações de diferentes culturas, em diferentes momentos históricos, e é uma ciência viva, que contribui para solucionar problemas científicos e tecnológicos e para alicerçar descobertas e construções, inclusive com impactos no mundo do trabalho (PLA, 2020). 
Tendo a BNCC como base teórica, o planejamento apresenta as habilidades para cada ano de estudo, com os conteúdos dispostos por ano e bimestre. Para revelar a evolução das aprendizagens durante o período,

A proposta de avaliação, aqui sugerida, esta pautada na concepção de avaliação formativa/mediadora numa perspectiva emancipatória, que tem o intento de contribuir para o êxito do ensino/aprendizagem, o que requer do professor e do estudante flexibilidade e vontade de adaptação, de ajustes. Uma avaliação que não é seguida de uma modificação das práticas do professor não tem chances de ser formativa (PLA, 2020).

$\mathrm{Na}$ intencionalidade de efetivar a avaliação na perspectiva acima descrita, os autores preconizam no planejamento anual alguns instrumentos a ser utilizados na prática pedagógica, no âmbito da sala de aula e nas atividades extraclasse. “Trabalhos individuais e/ou em grupo; avaliações dissertativas e/ou objetivas; relatórios; seminários e trabalhos”. Os critérios avaliativos a serem observados na trajetória do estudante são; “a participação nas discussões em sala de aula; assiduidade; correção do caderno em sala de aula e também correção das atividades extraclasses” (PLA, 2020). Ou seja, valoriza-se a participação dos alunos na realização das atividades propostas em sala de aula e fora dela, bem como o conhecimento demonstrado nas provas formais objetivas (múltipla escolha) ou discursivas, dissertativa (com o desenvolvimento da atividade na íntegra).

Diante do cenário descrito, este constructo contou com a colaboração de três professores do EM que atuam, há pelo menos cinco anos, na escola pesquisada, com o escopo de tecer uma reflexão crítica a respeito do processo de ensinoaprendizagem dos estudantes, com foco nos aspectos avaliativos, a partir da visão e das vivências destes profissionais da Matemática. Para preservar a identidade desses professores, foram utilizadas as siglas A, B, C para os nomes.

\section{Resultados}

Os resultados da pesquisa tiveram foco na postura do estudante diante do estudo na mudança de etapa; no seu conhecimento matemático básico construído no EF; os instrumentos avaliativos utilizados pelos docentes, durante o percurso do ano letivo, por meio de narrativas relatadas pelos professores de Matemática em resposta aos quesitos construídos no questionário.

Os docentes, ao serem inquiridos sobre a postura dos estudantes, na mudança de etapa do EF para o EM, algumas informações emergiram sobre a cultura estudantil na atualidade. Segundo a concepção dos professores colaboradores parte-se de duas concepções diferenciadas presente na perspectiva do senso comum: uma de que o Ciclo de Formação Humana, (modalidade vigente no EF na rede estadual) não reprova, e que, portanto, é desnecessário empreender muito esforço no sentido do estudo, da responsabilidade com a realização das atividades propostas, dado a ciência por parte dos estudantes da promoção progressiva. Outra de que o EM prepara os estudantes para o trabalho e para o ingresso no Ensino Superior e, que por isso, deve ser mais exigente, com uma gama maior de conteúdo. Tal perspectiva exige uma postura mais ativa dos alunos, maior responsabilidade sobre seu aprendizado, maior dedicação e disciplina na realização das atividades propostas em sala de aula, nos deveres de casa, nos trabalhos individuais e em grupo, sejam eles intra ou extraescolares, com avaliações mais padronizadas e, por vezes, seletivas.

Os padrões de conhecimento matemático, mínimos exigidos para progressão dos estudantes no EM, aparecem nas narrativas dos professores pesquisados, quando se objetivou conhecer como este público chega ao primeiro ano do EM, sua atitude diante do estudo e quais conceitos matemáticos de base foram construídos na etapa anterior. Para isso foi perguntado aos professores colaboradores:- "Com base em sua experiência profissional, você percebe que os estudantes concluintes do nono ano alcançaram o nível de conhecimento matemático suficiente para dar prosseguimento aos estudos no EM?” Dando- 
lhes opções de resposta objetiva que poderia ser: - sim, não, ou nem todos - seguido de uma explicação que mostrasse o motivo da escolha.

Obteve-se dos três professores atuantes na escola pesquisada, como resposta, um não e duas afirmações de que nem todos chegam com conhecimento matemático fundamental, ou seja, o básico necessário para prosseguir os estudos com chance de sucesso.

Quando perguntado quais saberes de base são necessários para que o estudante possa prosseguir nos estudos no EM, em entrevista posterior, foi esclarecido, por partes dos investigados, que uma parcela significativa destes estudantes chega a esta etapa sem saber a tabuada de multiplicação. O que, na visão destes professores, se trata de uma habilidade elementar e imprescindível, pois possibilita ao estudante transitar com desenvoltura nas demais operações. Outra situação mencionada foi a incapacidade destes estudantes de dominar as quatro operações fundamentais: adição, subtração, multiplicação e divisão com números naturais e inteiros. Essas lacunas de aprendizagem se acentuam no domínio destas operações como números racionais e em seus aspectos decimais. Foram também observadas dificuldades de trabalhar com as primeiras fórmulas de área e volume; princípios básicos de álgebra; identificação de termos semelhantes; conceitos e operações com potenciação e radiciação; compreensão sobre operações inversas; divisibilidade e simplificação de números racionais; equação de primeiro grau com identificação de primeiro e segundo termo, assim como sua resolução na forma mais simples; equação do segundo grau dentre outros. Os conhecimentos matemáticos citados são considerados básicos pelos sujeitos da pesquisa, os quais consideram que devem ter sido consolidados pelos estudantes no decorrer EF, pois na visão destes professores, não é possível construí-los do início no EM.

No que refere ao processo de identificação das aprendizagens prévias do alunado, quando perguntado aos professores se eles realizam avaliação diagnóstica dos estudantes que ingressam no EM, verificou-se que cada um, a seu modo, realiza ações nesse sentido.

A professora A afirma não utilizar um instrumento formal (prova) para aferir o conhecimento dos estudantes. Segundo ela, sua prática parte da análise do conteúdo programático para a etapa e "de acordo com o planejamento, verifico o conteúdo a ser trabalhado na série e quais são os conteúdos que os alunos deveriam saber para que consigam acompanhar. Feito o levantamento, faço uma revisão dos conteúdos bases”. Ela explicita ainda, que ao acompanhar o desenvolvimento das atividades propostas de revisão, consegue verificar quais estudantes tem desenvoltura nas resoluções e quais têm dificuldades/ defasagens no conteúdo. Quanto aos estudantes que se recusam a realizar os exercícios, estes vão sendo diagnosticados no diaa-dia com o decorrer do bimestre, se há uma defasagem muito acentuada ou apenas desinteresse pelo estudo da disciplina.

O professor B declara realizar avaliação diagnóstica e que esta "Serve como parâmetro para analisar ações qualitativas inclusive no planejamento", e que o acompanhamento dos estudantes por parte do professor durante a realização das atividades, mostra se uma ferramenta importante para conhecer e auxiliar o estudante durante o processo de ensino. A esse respeito, a professora $\mathrm{C}$ infere que "com a avaliação diagnóstica, consigo detectar como trabalhar com aquela turma os conteúdos específicos da série, ao identificar as fragilidades e planejar ações no sentido de corrigi-las”, mas enfatiza que com duas aulas semanais (de 55 minutos), muito pouco pode ser feito para resgatar conhecimentos negligenciados no EF. Esclarece ainda que turmas numerosas (trinta a trinta e cinco) alunos matriculados exigem dos professores muita dedicação, uma vez que a maior parte dos estudantes encontra-se com dificuldade de avançar nos conteúdos do EM.

Ainda no que alude aos conhecimentos matemáticos trazidos do $\mathrm{EF}$, há unanimidade em dizer que parte destes estudantes não assimilou em nove anos de escolarização, conceitos básicos necessários para dar prosseguimento aos estudos com chance de sucesso. Destaca-se, segundo A, que esta parcela chega ao EM com "conteúdo matemático defasado, ou até mesmo sem saber quase nada", estão divididos em dois grupos segundo a professora, "alunos com muita dificuldade [...] mas que se esforçam em aprender, [...] e os que não demonstram um mínimo interesse pela disciplina”. 
Segundo os professores (as) investigados (as), ao serem questionados sobre quais instrumentos utilizam para verificar a evolução da aprendizagem dos estudantes, alguns relatos se destacam. A afirma que utiliza "as atividades diárias desenvolvidas em sala: observa se o aluno desenvolve, se pergunta, se a dúvida dele condiz com as habilidades em questão ou se seria habilidades que já deveriam estar claras para ele (de outras séries), e uma prova por bimestre". B enfatiza a mescla de instrumentos e métodos que vão desde "trabalhos, provas, apresentações de grupo, participação em aula, autoavaliação, testes, vídeos, feedback de reforço, gráficos estatísticos até mesmo entrevistas para tabular ação" enquanto $\mathrm{C}$, de forma resumida, coloca que avalia os estudantes "através de provas, trabalhos e as atividades de sala de aula".

Dentre os aspectos considerados importantes para promoção dos estudantes ao final do curso, estão na visão de A "o comprometimento do aluno com seu aprendizado. Se este aluno desenvolve as atividades solicitadas, se tem coerência nas resoluções". Para B, observando a heterogeneidade dos estudantes, considera que a "participação em classe é muito importante, projeto extraclasse, autoavaliação e socialização de aprendizado com os pares”. Já para C, um critério preponderante para promoção dos estudantes é "a participação do aluno nas aulas, o desejo que ele tem de aprender mesmo com grande dificuldade no aprendizado". Destarte, todo o esforço apresentado pelos estudantes é agregado à assimilação dos conteúdos para compor o veredicto final.

\section{Considerações Finais}

Com base nos dados coletados na pesquisa, é possível tecer algumas considerações acerca de três importantes elementos inerentes ao processo educativo, indissociáveis entre si, que são: a postura e compromisso do estudante diante do estudo; os saberes matemáticos de base construídos no EF e; a forma de diagnóstico e avaliação desses saberes no primeiro ano do EM. Fatores que se entrelaçam e convergem para um único desfecho para o estudante: a promoção; a retenção ou o abandono.

Algumas observações acerca da denominação avaliação emergem das informações obtidas nos documentos e nas falas dos colaboradores. Ao iniciar uma conversa com os docentes sobre a temática avaliação, a primeira interpretação que surge é que este termo remete a prova. Esse conceito de que são palavras sinônimas é cultural e está presente no Projeto Político e Pedagógico da escola (2021), ao se referir à avaliação unificada, como mecanismo de avaliação. O PLA sugere a mesma interpretação onde se lê "avaliações dissertativas e/ou objetivas" ao elencar os instrumentos prospectado. Destaca-se ainda a intencionalidade teórica em propor a concepção de "avaliação formativa/mediadora numa perspectiva emancipatória" e pressupõe a necessidade da flexibilidade do professor e do docente para sua concretização. Na visão de Luckesi (2018), tal concepção só é possível se a proposta pedagógica e o currículo forem pensados e desenvolvidos nessa perspectiva e que, a avaliação sozinha tampouco consegue atender a esses critérios. É também primordial que haja condições de trabalho favoráveis a sua efetivação.

O PPP (2021) afirma que as progressões e dificuldades no desenvolvimento dos conceitos matemáticos dos estudantes durante o processo são observadas, mas que o sistema de monitoramento é falho, ou seja, não se analisa em profundidade essas defasagens, no sentido de propor ações de correção delas no curso da aprendizagem. Isso se deve, segundo o documento, à não adoção de metodologias alternativas de avaliação, por todo o corpo docente. Apesar de propor uma variedade de instrumentos e técnicas que subsidie uma avaliação formativa e processual eficiente, não há um entendimento unânime sobre a avaliação proposta. Ressalta ainda que, tais instrumentos e metodologias precisam ser aperfeiçoados e que a evolução do estudante necessita ser discutida entre os docentes, antes da efetivação das notas e/ou conceitos, que sinalizam para o possível desfecho da situação do estudante ao final do processo.

Os três professores investigados afirmam que a progressão continuada do ciclo de formação humana cria no estudante a cultura da não reprovação e, por isso, o descompromisso com o estudo. Dessa postura advém a grande defasagem na 
aprendizagem de conteúdos e conceitos matemáticos fundamentais necessários à continuidade do curso no EM. Com regime seriado, a promoção se dá mediante a verificação da assimilação do que é ensinado.

Essa ruptura no processo educativo e na concepção avaliativa se desdobra na seguinte problemática: assim como os docentes, grande parte dos estudantes vivenciou o processo do ciclo por nove anos e chegam ao EM sem terem consolidado habilidades elementares da disciplina. Ao ingressar na nova etapa, são inseridos em salas de aula numerosas com apenas duas aulas semanais. Nesse cenário, as medidas de recuperação paralela, em sua maioria, acabam por não surtir o efeito desejado frente à necessidade de resgatar e (re)construir essas habilidades, desde o princípio.

Considera-se, no entanto, que parte dos estudantes demonstra certo esforço e, mesmo com grande dificuldade, consegue algum progresso e é aprovada, outra desiste da disciplina, amparada pela possibilidade de cursá-la em dependência. Uma parcela ainda, simplesmente, não avança e desiste da escola ou da disciplina e, por isso, não evolui. Por vezes, os discentes são retidos por ultrapassar o limite máximo de quatro dependências das doze disciplinas da grade. Além disso, o não progresso, no EM, se ampara em algumas suposições, segundo o olhar dos professores: falta de habilidades básicas devido ao descompromisso com os estudos; à cultura da não reprovação do ciclo; à falta de valorização dos saberes proporcionado pela escola por parte da família com o não acompanhamento da vida estudantil dos (as) filhos (as); ao tempo limitado de aula que dificulta o processo de realização de recuperação paralela; à ausência de estrutura física e de uma proposta pedagógica que seja capaz de realizar um programa eficaz de recuperação no contra turno.

A ação interventiva de recuperação e reforço escolar já esbarra em outras variáveis que vão além da competência dos professores, como: a utilização de transporte escolar que inviabiliza o retorno destes estudantes no período oposto; discentes que trabalham no contra turno; falta de apoio, incentivo e auxílio da família nas atividades de reforço, etc.

Esses são alguns dos fatores internos e externos que aparecem nas considerações dos colaboradores e que fogem da alçada da instituição de ensino e da atuação docente, podendo estar associados à retenção e ao abandono dos estudantes do primeiro ano do EM.

O contexto da avaliação da aprendizagem, diante dessa realidade revelada pelos sujeitos da pesquisa, fica em parte comprometido uma vez que, ao avaliarem a assimilação do que foi ensinado, nem sempre conseguem aplicar intervenções pedagógicas que alcancem a todos, mas apenas uma parte dos estudantes.

Em mérito aos métodos e instrumentos citados pelos professores pesquisados, seja de modo formal (provas) ou informal, atividades avaliativas ou de acompanhamento diário, a prática avaliativa dentro do contexto do EM da rede estadual de MT, de acordo com os fundamentos teóricos da avaliação da aprendizagem escolar, apresenta traços de formação e de exame. O que na visão de Sacristán e Gómez (1998, p. 329) “[...] em quaisquer das concepções - formal com provas ou informal com acompanhamento pessoal - a função diagnóstica exige uma atuação profissional bastante intensa em dedicação de tempo aos alunos/as, só e possível se eles são poucos”.

Nesse sentido, com duas aulas semanais em turmas numerosas e de saberes heterogêneos, pode-se afirmar que o professor consegue ensinar a todos, mas jamais garantirá aprendizagem suficiente a cada um deles. Destarte, a avaliação praticada inclui uma parte dos estudantes e exclui outra. O que confirma que a teoria da avaliação da aprendizagem que, em sua definição, é revelar a qualidade dos processos formativos, para propor a correção no curso das aprendizagens com abordagens metodológicas que alcancem a todos, de modo que não deixe ninguém para trás, em termos de conhecimento, não se efetiva diante da realidade vivenciada por alunos e professores da Educação Básica da rede estadual de MT, especificamente do primeiro ano do EM. 


\section{Referências}

Bogdan, R., \& Biklen, S. K. (1994). Investigação qualitativa em educação: uma introdução à teoria dos métodos. Porto.

Lei $\mathrm{n}^{\mathrm{o}}$ 9.394/96, de 20 de dezembro. (1996). Estabelece as diretrizes e bases da educação nacional. Brasília, DF. http://www.planalto.gov.br/ccivil_03/leis/19394.htm

Ministério da Educação. (2016) Base Nacional Comum Curricular. Brasília, DF. Recuperado de http://basenacionalcomum.mec.gov.br/\#/site/inicio.

Ministério da Educação. (2017). Base Nacional Comum Curricular. Brasília, DF. http://basenacionalcomum.mec.gov.br/imag es/historico/BNCC_EnsinoMedio_embaixa_site_110518.pdf.

Creswell, J. W. (2014). Investigação qualitativa e projeto de pesquisa: escolhendo entre cinco abordagens. In F Rosa, S.M. (Trad.) \& Silva, D. (rev. Técnica). $\left(3^{\mathrm{a}}\right.$. ed.) Porto Alegre, RS: Penso.

Darsie, M. M. P. (1996). Avaliação e aprendizagem. Caderno de pesquisa. 99 (6) 47-59. http://publicacoes.fcc.org.br/index.php/cp/article/view/785/797.

Gil, A. C. (1999). Métodos e técnica da pesquisa social. Atlas.

Hoffmann, J. (2018). Avaliação mediadora: uma pratica em construção da pré-escola a universidade. (34a ed.) Mediação.

Hoffmann, J. (2018). Avaliar para promover; as setas do caminho. (17a ed.) mediação.

Libâneo, J. C. (2006). Didática. São Paulo, Editora Cortez.

Libâneo, J. C (2015). Organização e Gestão da escola: teoria e pratica. (6a ed.) Heccus.

Luckesi, C. C. (2011). Avaliação da aprendizagem escolar: estudos em proposições. Cortez.

Luckesi, C. C. (2018). Avaliação em educação: questões epistemológicas e práticas. Cortez.

Orientações Curriculares (2012). Concepções para a Educação Básica [OCEB]. Secretaria de Estado de Educação. Gráfica Print.

Portaria $n^{\circ} 684$ de 03 de dezembro de 2020. (2020). Dispõe sobre fluxo, critérios e prazo para processo de criação e disponibilização de matrizes curriculares para os cursos da Educação Básica, bem como define critérios para composição de turmas das Unidades Escolares da Rede Publica Estadual de Ensino. Diário Oficial (N 27.890. p 82). Recuperado de https://www.iomat.mt.gov.br/portal/visualizacoes/jornal/16123/\#/p:82/e:16123

Lei Complementar No 50 de 01 de outubro de 1998. (1998). Dispõe sobre a Carreira dos Profissionais da Educação Básica de Mato Grosso. http://webcache.googleusercontent.com/search?q=cache:Cf0699TzoH4J:www.gestao.mt.gov.br/download.php\%3FOp\%3Dlegislacao\%26arquivo\%3DLC_501998-160.pdf $+\& \mathrm{~cd}=1 \& \mathrm{hl}=\mathrm{pt}-\mathrm{BR} \& \mathrm{ct}=\mathrm{clnk} \& \mathrm{gl}=\mathrm{br} \& \mathrm{client}=$ firefox-b-d.

Moraes, R. (2003). Uma tempestade de luz: a compreensão possibilitada pela análise textual discursiva. Ciênc. educ. 9(2) 191-211.

Moraes, R. \& Galiazzi, M. C. (2016). Análise textual discursiva. (3a ed.) Revista Ampliada

Perrenoud, P. (1999). Avaliação: da excelência a regulação das aprendizagens - entre duas lógicas. In Ramos, P.C. Artmed.

Sacristán, J. G. \& Gómez, A. J. P. (1998) A avaliação no ensino. In Ernani. F. da F. R. (Trad.). Compreender e transformar o Ensino. (4a ed.), $295-331$. Artmed.

Escola Estadual Nilza de Oliveira Pipino (2019-2021). Projeto Político Pedagógico. [SEDUC]. Sinop. MT

Escola Estadual Nilza de Oliveira Pipino (2020). Planejamento Anual dos professores de Matemática. [SEDUC]. Sinop. MT 